\title{
Application Research of Industrial Product Design Trend in 5G Perspective
}

\author{
ZHANGHai-chao, WANGLi \\ Dalian University of Science and Technology, China \\ Dalian University of Science and Technology, China
}

\begin{abstract}
This article analyzes the characteristics of industrial product design in the $5 \mathrm{G}$ era, and describes the application of $5 \mathrm{G}$ technology in industrial product design. It is mainly reflected in changing product interaction methods, industrial Internet development, and application scenario changes. Finally, in the context of the $5 \mathrm{G}$ era the development trend of industrial product design is expected, and product design will achieve greater development in the direction of intelligence, IoT, and cloudification.
\end{abstract}

\section{Introduction}

In the context of the $5 \mathrm{G}$ era, computer technology is developing rapidly, and humans have entered the era of information explosion, which not only changes social technology characteristics, but also affects all aspects of human production and life. Based on this, industrial product design has also changed. Now that the $5 \mathrm{G}$ era is coming, the design of industrial products should develop in the direction of intelligence and cloudification, and become innovative products that better meet people's needs.

\section{Features of industrial product design in the $\mathbf{5 G}$ era}

\subsection{The relationship between computer technology and design}

With the rapid development of computer technology, not only the traditional design technology changes, but also the design procedures and methods. In order to meet the new requirements, the designer 's concept and thinking should also change. At the same time, more and more high-tech are being researched, represented by $5 \mathrm{G}$ technology, which has opened up a new field for industrial product design. Advanced technology and The organic combination of excellent design makes the technology more humane, makes it truly serve humanity, and has an important impact on the advancement of high-tech products.

\subsection{Computer Aided Design}

In the context of the $5 \mathrm{G}$ era, computer systems can complete many transactional and repetitive tasks. In the design of industrial products, some machines cannot be completed, and things that require independent thinking are created by designers to improve the work of technology-intensive talents. The situation of labor-intensive work has also become a distinctive feature of the new era. In the past 50 years, industrial design has officially entered a period of great development and prosperity, especially in the context of the $5 \mathrm{G}$ era. The rise and application of computer technology has greatly promoted the development of industrial design, and the design speed has continued to increase, helping design to complete a lot of rationality. Work, designers have more time and energy to devote to concept analysis and creative design [1].

\section{Application of 25G technology in industrial product design}

\subsection{Changing the way products interact}

Interaction design relies heavily on products. Especially in the context of $5 \mathrm{G}$, the integration of industrial products and new technologies paves the way for interaction design. Compared with the past, the interaction mode of the product has changed, which is mainly reflected in the three levels of touch, vision and hearing.

Tactile interaction. This method is the main means for people to manipulate products. In the context of the 5G era, technology has become more mature and complete. From previous mechanical buttons to electronic displays, and then to virtual screens, the interaction details of industrial products have changed significantly. At present, smart wearable devices can read data information by contacting a certain part of the human body to achieve goals such as recording steps, monitoring mentality, and monitoring sleep. In product 
applications, the tactile interface enables people to directly interact with the virtual environment. In the virtual environment, they can feel the state of the object with their hands and issue instructions. At the same time, they can also give feedback by sensing gestures.

Visual interaction. This method is an interactive method using communication and communication. It has the characteristics of large amount of information and fast dissemination. During the interaction process, the two senses, the audiovisual, interact with each other. However, when people interact with machines, they only need to rely on vision to obtain a large amount of information. Robots can perceive visual information by "observing" people. Under the application of 5G technology, people can also use contact lenses to enhance reality perception. Enabling the separation of the digital environment.

Auditory interaction. In essence, this type of interaction is equivalent to speech recognition. It not only recognizes the acoustic information, but also pays attention to reconstructed words, dialog background and syntax, etc., making the speech recognition more accurate and efficient. In the past, some scientists have predicted that the next revolution in computers will shift from graphics to speech. After the birth of TNT technology, the development space of auditory interaction technology has been further expanded [2].

\subsection{Development of the Industrial Internet}

2019 is known as the first year of 5G. The Internet economy is unprecedentedly prosperous, and Internet consumption is rising. After 2019, 5G technology will reshape the IT era, tightly integrate industrial product design with the Internet, and lead the industrial Internet to achieve greater development. Compared with $4 \mathrm{G}$ technology, 5G has some changes in functions, features and objects, as shown in Table 1 below. The Industrial Internet is a combination of industrial manufacturing, analytical computing, and network technology to form a comprehensive, brand-new network. This concept defines the core elements of the Internet, including the three aspects of equipment, people, and data. In the Industrial Internet, it can achieve the in-depth integration of information technology and manufacturing industries, and provide important support for the arrival of the new industrial revolution.

After the concept of "Industry 4.0" was introduced in Germany, China formally proposed the "Made in China 2025 " goal, and the United States subsequently proposed the concept of the Industrial Internet. From then on, sparks began to strike between manufacturing and the Internet, which also symbolized industry The collision with the two eras of information. From the standpoint of our country, the industrial and information sector is preparing to build 10 national-level network platforms. From the perspective of globalization, the number of industrial Internet platforms that have been built exceeds 150. The construction of such platforms has become the general trend. To help the manufacturing industry save a lot of costs and work more efficiently. In the sale of
Internet products, the relationship between customers and enterprises has changed substantially, and customers occupy a dominant position. This move is bound to fully stimulate the vitality of enterprises, make them stronger and stronger in competition, and achieve greater development [3].

In the context of $5 \mathrm{G}$, computer performance continues to improve, and machine learning continues to develop. It can train through huge amounts of data and generate corresponding forms based on the collected data. Taking the Hack Rod racing design as an example, sensor capture data is used to feedback the physical factors of the vehicle and driver. From this, the vehicle chassis is calculated and generated, as shown in Figure 1 below. The design is to use a number of data sources to build a parameterized system in the context of the Industrial Internet. After the data is collected, the designer converts key information into mechanical conditions.

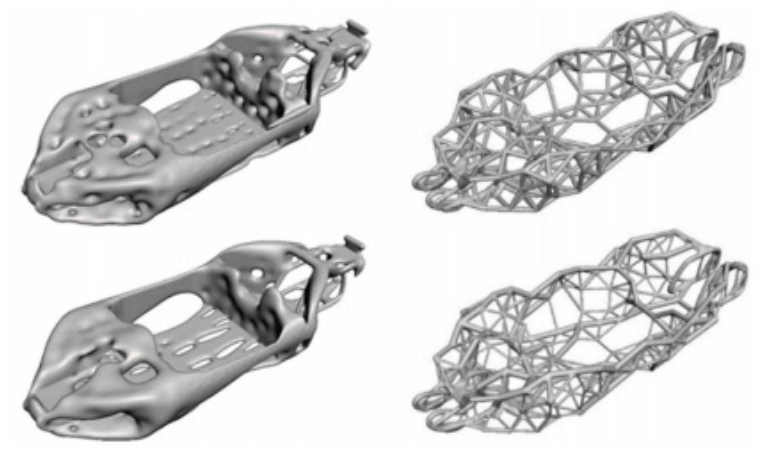

Figure 1. Hack Rod generation process

\subsection{G application scenarios}

As one of the most advanced technologies, 5G technology is applicable in many scenarios, including eMBB, uRLLC, and mMTC. They all have strong reliability, mobile broadband, large-capacity communication, and low latency. For example, in a factory scenario, uRLLC can achieve low-latency transmission, shorten network latency, and realize real-time network transmission, providing support for the synchronization and sharing of important data in the factory; eMBB applications can support video conferences, remote monitoring, etc., and promote field Internal and external communication and interworking. 
Table 2 Application of three major scenarios in 5G background

\begin{tabular}{cccc}
\hline & uRLLC & eMBB & mMTC \\
\hline Business & $\begin{array}{c}\text { Industrial } \\
\text { Automation } \\
\text { Business }\end{array}$ & 3D, Ultra HD video & $\begin{array}{c}\text { High-volume IoT } \\
\text { business }\end{array}$ \\
Application scenario & $\begin{array}{c}\text { Data transmission } \\
\text { reduced to less than } \\
1 \mathrm{~ms}\end{array}$ & $\begin{array}{c}\text { Remote monitoring, } \\
\text { video conference }\end{array}$ & $\begin{array}{c}\text { Low power, } \\
\text { embedded terminal }\end{array}$ \\
\hline
\end{tabular}

wearable industrial products have been widely used in

\section{The development trend of industrial product design in the context of the 35G era}

\section{$4.1 \mathrm{loT}$}

The Internet of Things is a network constructed on the basis of the traditional Internet, telecommunications network, and other information carriers. It enables all objects to complete this function independently and enables objects to communicate with each other. At present, the $5 \mathrm{G}$ era is coming, and the infrastructure of the Internet of Things is faster. It can play a key role in many fields such as the Industrial Internet, vehicle networks, and medical industries., Can achieve the goal of Internet of Everything. The main role of the Internet of Things is to collect data. The source of the information is sensing equipment, which can interact with and interact with the information in the network database to achieve intelligent identification and management. The use of the Internet of Things is very broad, and can be combined with many aspects such as urban construction, medical care, agriculture, etc. to achieve intelligent development. In addition, there are some areas that overlap with intelligence, such as smart homes. Industrial designers are required to establish IoT thinking, design smart air conditioners, smart security systems, smart table lamps, and so on.

In the context of the $5 \mathrm{G}$ era, industrial products will have ultra-high reliability and ultra-low latency, which will largely promote the development of autonomous driving, smart medical and other fields. Taking automatic driving as an example, based on the Internet of Vehicles, a variety of data information is collected, intelligent algorithms are used to monitor vehicle operating conditions, and the collected information is optimized. In addition, combining the Internet of Things with medical equipment can provide patients with more high-quality and considerate services, and also can connect hospital registration, payment, rounds and other services, providing more convenience for medical staff.

\subsection{Intelligent}

Fundamentally, there is a difference between intelligent and IoT, but the two are inclusive and closely related. Intelligent objects are closer to civilian use, and smart the market, such as intelligent robots (home), intelligent parking, etc., and gradually enter people's lives. In future development, intelligence has a large space for development in terms of user perception, network analysis, system optimization, and network value mining [4].

\subsection{Cloudification}

For industrial enterprises, enterprises need to go through the cloud in four stages, including basic systems, management, cloud, core business, and ecological services. In this process, security, stability, and low cost are fully reflected. And strong management. Cloudification can make the Internet of Things industry expand invisibly, make the internal connections of enterprises closer, and make the division of ecology clearer. In the context of the $5 \mathrm{G}$ era, cloud VR has become a hot topic in the field of virtual reality. Based on the industrial ecology field, a cloud-end collaborative virtual reality network distribution platform is being constructed, and the aggregation platform is continuously developing in a more efficient, secure, and reliable direction. In the process of cloud-based construction, it is bound to break free of constraints, make $5 \mathrm{G}$ cloud-based VR more systematic and large-scale, and promote its application in more applications.

\section{Conclusion}

In terms of industrial product design, in order to design smarter and more innovative products, it is necessary to strengthen the integration with computer technology. In the context of the $4 \mathrm{G}$ and $5 \mathrm{G}$ era, lead industrial design to be more intelligent. The development path enables people to realize a smart life at an early date.

\section{References}

1. Yang Lin. Industrial Product Design in the Information Age [J]. New Curriculum Study (Chinese), 2018 (2): 65.

2. XiongMeiling, Ye Shuanggui. Impact of $5 \mathrm{G}$ technology on industrial product design $[\mathrm{J}]$. Art and Design (Theory), 2019 (11): 90.

3. Zhang Wei. Application of green design in industrial product design $[\mathrm{J}]$. Hebei Industrial Science \& 
Technology, 2019 (04): 57-59.

4. Luo Jian. Application of Ergonomics in Industrial Product Design [J]. Mechatronic Engineering Technology, 2018, 33 (3): 9-11.

5. Zhang Yunyong. 5g will fully enable industrial Internet $[\mathrm{J}]$. Telecommunication science, 2019, 35 (01): 1-8.

6. Xu Zefu. Transformation of Internet of things in $5 \mathrm{~g}$ era [J / OL]. Electromechanical engineering technology 2019 (S1): 69-71 [2019-09-29]. 